\title{
PID Testing Method Suitable for Process Control of Solar Cells Mass Production
}

\author{
Xianfang Gou, ${ }^{1,2}$ Xiaoyan Li, ${ }^{1}$ Su Zhou, ${ }^{2}$ Shaoliang Wang, \\ Weitao Fan, ${ }^{2}$ and Qingsong Huang ${ }^{2}$ \\ ${ }^{1}$ Beijing University of Technology, Beijing 100124, China \\ ${ }^{2}$ CECEP Solar Energy Technology (Zhenjiang) Co., Ltd., Zhenjiang 212132, China \\ ${ }^{3}$ Beijing Jiaotong University, Beijing 100044, China \\ Correspondence should be addressed to Su Zhou; zhousu2003@hotmail.com
}

Received 4 September 2015; Accepted 5 October 2015

Academic Editor: Xudong Zhao

Copyright (C) 2015 Xianfang Gou et al. This is an open access article distributed under the Creative Commons Attribution License, which permits unrestricted use, distribution, and reproduction in any medium, provided the original work is properly cited.

Voltage bias of several hundred volts which are applied between solar cells and module frames may lead to significant power losses, so-called potential-induced degradation (PID), in normal photovoltaic (PV) installations system. Modules and minimodules are used to conduct PID test of solar cells. The test procedure is time consuming and of high cost, which cannot be used as process monitoring method during solar cells fabrication. In this paper, three kinds of test including minimodule, $R_{\mathrm{sh}}$, and V-Q test are conducted on solar cells or wafers with $\mathrm{SiN}_{x}$ of different refractive index. All comparisons between test results of $R_{\mathrm{sh}}, \mathrm{V}-\mathrm{Q}$, and minimodule tests have shown equal results. It is shown that $R_{\mathrm{sh}}$ test can be used as quality inspection of solar cells and V-Q test of coated wafer can be used as process control of solar cells.

\section{Introduction}

In standard photovoltaic (PV) installations system, PV modules are exposed to voltage bias of several hundred volts with respect to the module frames/mounting [1-3]. Due to those high voltages, solar modules may suffer so-called potentialinduced degradation (PID) which may lead to significant performance loss [4-6]. It is reported that high voltages may lead to leakage currents through the encapsulating material, being responsible for degradation effects [7]. Some investigation revealed that soda lime glass, ethylene vinyl acetate (EVA), and the solar cell's antireflective coating (ARC) play important roles in the formation of PID [8-10].

Among those factors, antireflective coating (ARC) was the important part and was widely studied to avoid PID [11, 12]. Solar cells with $\mathrm{SiO}_{2} / \mathrm{SiN}_{x}$ double coating layer or $\mathrm{SiN}_{x}$ with high reflective index all have great improvement. At present, most PID test methods about solar cells are conducted on modules [13] or minimodules $[9,14]$. Solar cells firstly should be made into module and then placed in an environmental chamber under defined conditions, finally connected to a power supply in order to generate a typical bias voltage for defined times. The test procedure is time consuming and of high cost, which cannot be used as process monitoring method during solar cells fabrication.

The purpose of this work was to provide simple and fast PID test methods about solar cells which are suitable for quality inspection of solar cells and process control of ARC deposition during mass production.

\section{Experimental}

Solar cells based on p-type multicrystalline wafers with resistivity of $1-3 \Omega \cdot \mathrm{cm}$ and thicknesses of about $190 \mu \mathrm{m}$ were used as test samples. Solar cells with different $\mathrm{SiN}_{x}$ refractive index were divided into different groups according to various anti-PID properties. The PID performances of solar cells were evaluated by three methods, including minimodule test, shunt resistance $R_{\mathrm{sh}}$ test, and voltage-corona charge (V-Q) test for solar cells. Same EVA and glasses were used for minimodule test and $R_{\mathrm{sh}}$ test. The test results of three different methods were compared to each other to investigate the substitutability of those methods. 


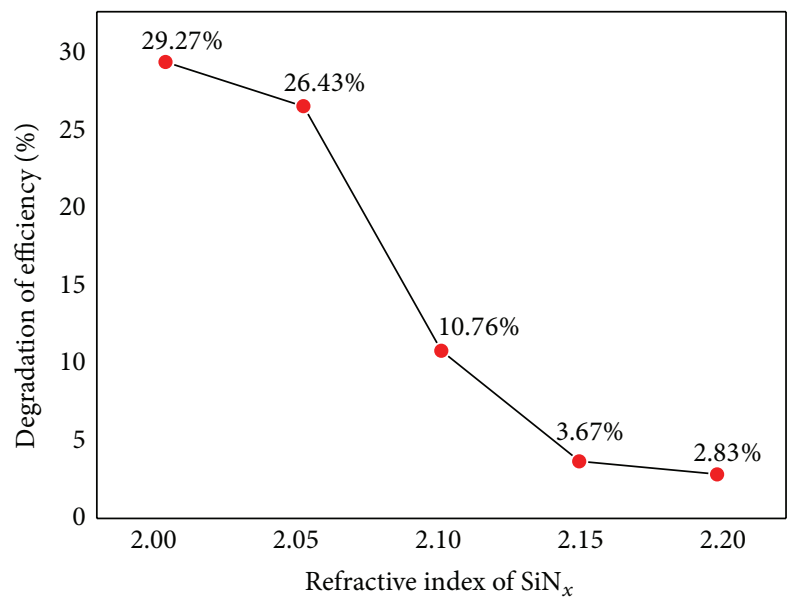

FIGURE 1: Different PID power loss of cells with ARC of different refractive index.

Frameless minimodules (one mc-Si cell, dimensions $30 *$ $30 \mathrm{~cm}^{2}$ ) were used for the lab testing with a self-adhesive aluminum tape as a substitute for the frame. Some water was dropped on the surface of glass and then another aluminum foil was applied on the top of glass to ensure full contact between glass and aluminum tape. The PID test was conducted in environment chamber with temperature of $85^{\circ} \mathrm{C}$, humidity of $85 \%$, applied voltage of $1000 \mathrm{~V}$, and time of $96 \mathrm{~h}$. The electrical parameters and EL image were measured to evaluate the PID performance of solar cells.

$R_{\mathrm{sh}}$ test was performed using PIDcon which was developed by Fraunhofer CSP and now is commercially available by Freiberg Instruments [15] as follows: the solar cell was placed on a temperature-controlled aluminum chuck to achieve a constant temperature throughout the testing process. On the front side, a sheet of EVA and glass were placed on top of the solar cell. The front surface of the solar cell was connected to a needle to measure the solar cell parameters. A solid metal block was then placed on top of the front glass to achieve a uniform high voltage across the glass surface within the test area. A voltage of $1000 \mathrm{~V}$ was then applied between the front metal block and aluminum chuck. During the degradation, the shunt resistance of the solar cells was measured to indicate the performance change of solar cells. Cells of different group with similar initial $R_{\text {sh }}$ were chosen as test samples.

$\mathrm{V}-\mathrm{Q}$ characteristics of ARC films were also measured to evaluate the conductivity of these films using WT-2000 PVN from Semilab [8]. After ARC coating, silicon wafers are charged by corona continuously. Kelvin Probe was used to measure the surface voltage of silicon wafer under different charged electric quantity. Generally, the surface voltage initially increases with the charged electric quantity and then is gradually saturated with a certain voltage which was named $V_{\text {limit }}$. The value of $V_{\text {limit }}$ can be used to evaluate the conductivity of ARC film.

\section{Results and Discussion}

3.1. Minimodule Test. Figure 1 shows the different PID power loss of cells with ARC of different refractive index. The thickness of film was controlled to the same ( $85 \mathrm{~nm})$, and different refractive index is produced by adjusting the flow rate of silane and ammonia in the process of deposition. It can be seen from the figure that the PID power loss decreases from $29.27 \%$ to $2.83 \%$ while the refractive index changes from 2.0 to 2.2. The results show that the PID decreases by the increasing of refractive index of $\mathrm{SiN}_{x}$, especially when the refractive increases from 2.0 to 2.15 , and the PID shows sharply downward trend and then comes to a slightly decreased trend. By the increasing of refractive index of $\mathrm{SiN}_{x}$, the brightness in EL is enhanced gradually before PID test. After PID test, the point of darkness in EL picture increases for the low refractive index. When the refractive index increased to 2.2, the testing results show it is stable after the PID, indicating a good antiPID performance. The EL images also verified that higher refractive index of $\mathrm{SiN}_{x}$ can weaken PID of solar cells and even eliminate this phenomenon (Figure 2).

3.2. PIDcon Test. Figure 3 shows the degradation of $R_{\mathrm{sh}}$ of different $\mathrm{SiN}_{x}$ refractive index. In order to make accurate comparison, solar cells with $R_{\text {sh }}$ of 100-300 $\Omega$ were chosen to apply PIDcon test. It can be seen that, in the process of refractive index changing from 2.0 to 2.2 , the $R_{\mathrm{sh}}$ degradation rate varies from being rapid to almost stable. It indicates that the $R_{\mathrm{sh}}$ degradation rate decreases by the increasing of refractive index of $\operatorname{SiN}_{x}$. Plenty of reports claim that the decrease of $R_{\text {sh }}$ is a very important parameter in evaluation of the PID problem. When $R_{\text {sh }}$ of solar cells decreases to an extremely low level, for example, lower than $5 \%$, it will have an obvious negative effect on solar cell output parameters.

3.3. V-Q Test. Figure 4(a) shows the relation between the surface voltage of silicon with $\mathrm{SiN}_{x}$ films and the deposited corona charge density under different refractive index of $\mathrm{SiN}_{x}$. The surface voltage increases with more positive corona charge on the surface. For samples with high refractive index, such as 2.1,2.15, and 2.2, the voltage is easy to become saturate. And for samples with low refractive index, such as 2.0 and 2.05 , it seems that it needs higher corona charge density to lead the voltage to saturation. It can be seen that, by 


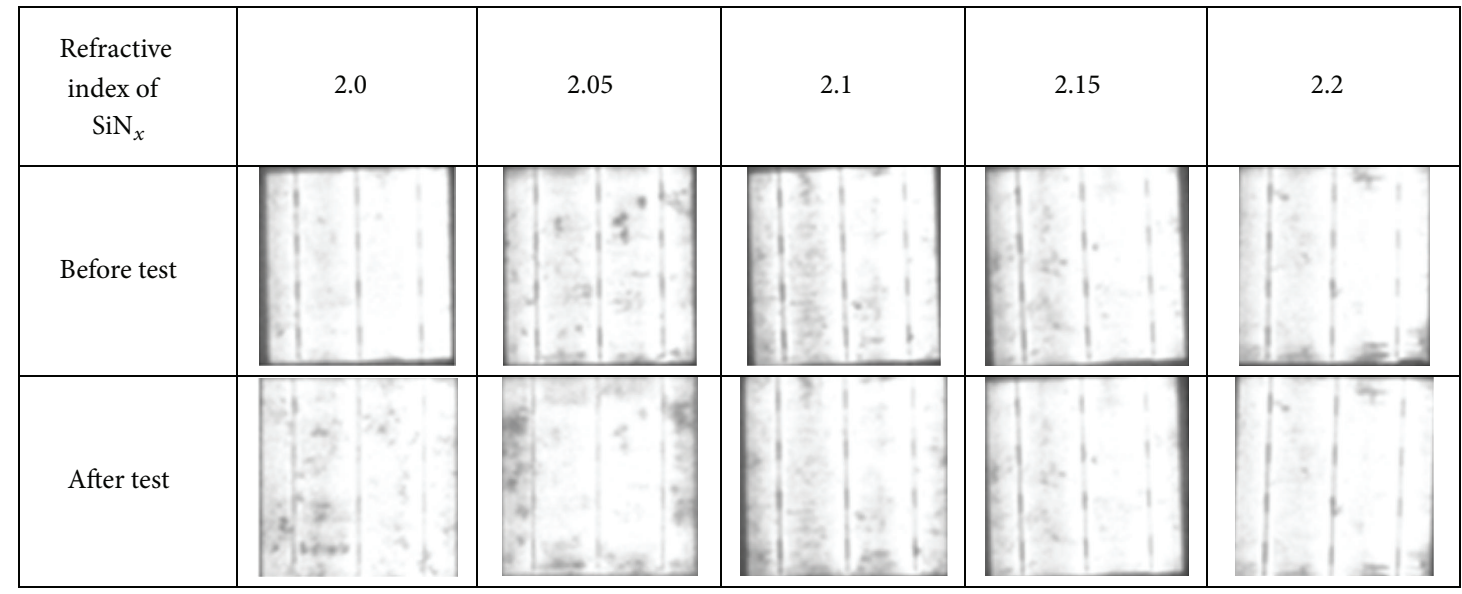

FIGURE 2: Different EL images of cells with ARC of different refractive index before and after PID test.

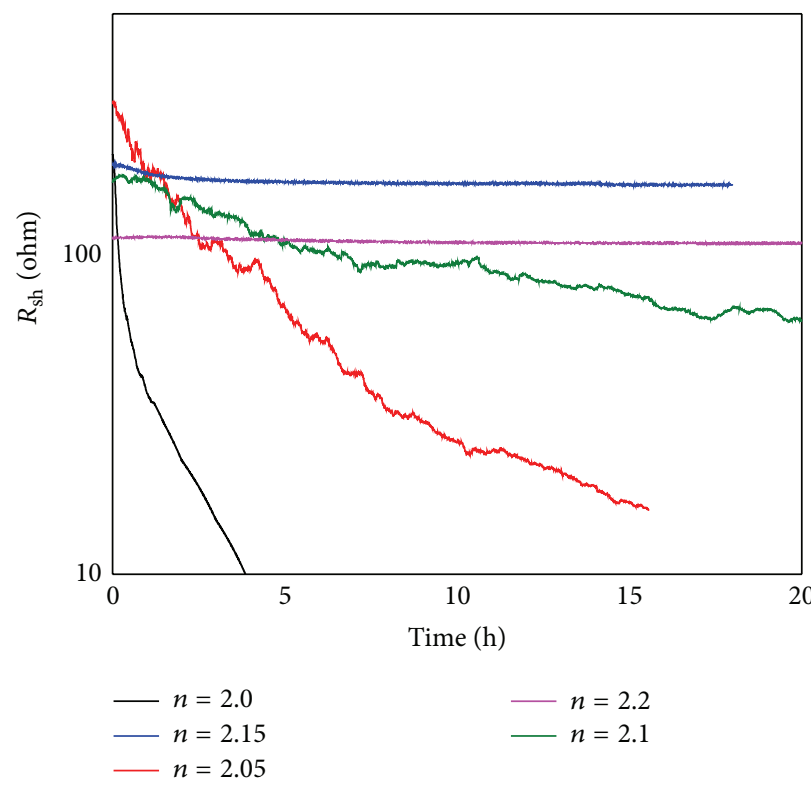

Figure 3: Degradation of $R_{\mathrm{sh}}$ of different $\mathrm{SiN}_{x}$ refractive index.

the increasing of the refractive index of $\mathrm{SiN}_{x}$, while positive corona charge was applied on the ARC surface, the voltage may reach the saturation state more easily. Once the voltage reached the saturation state, the voltage does not change by more corona charging. It can be explained by the leakage current through ARC. Continuous positive charging will leak out because of the electrical conductivity of ARC film. The saturation voltage was extracted from Figure 4(a) and plotted with refractive index of $\operatorname{SiN}_{x}$ in Figure 4(b). It has to be mentioned that, for samples with refractive index of 2.0 and 2.05 , the saturation voltage is extracted by the voltage of the maximum corona charge density $\left(3000 \mathrm{nC} / \mathrm{cm}^{2}\right)$.

The saturation voltage decreases with the increasing of refractive index. When the refractive index increased from 2.0 to 2.1, the saturation voltage decreased from $29.1 \mathrm{~V}$ to $6.6 \mathrm{~V}$ rapidly. Then the value of $V_{\text {limit }}$ changes slightly by increasing refractive index. Low $V_{\text {limit }}$ indicates an increased electronic conductivity, arising from more mobile electrons, in the silicon rich $\mathrm{SiN}_{x}$ layer with higher refractive index. In comparison of the minimodule, $R_{\mathrm{sh}}$, and V-Q result, the function of represented parameter with refractive index takes the same trend. Then they are the equal test tool to evaluate the performance of PID in silicon solar cells.

\section{Conclusion}

Modules or minimodules PID tests are quite time consuming and of high cost. In this paper two sample methods for checking the PID performance of solar cells and ARC coating were provided to solve the monitoring problem during mass production of anti-PID solar cells. All comparisons between $R_{\text {sh }}, \mathrm{V}$-Q test of silicon solar cell, and minimodule tests in climate chambers have shown equal results. And $R_{\mathrm{sh}}$ and V-Q test are much simpler than minimodule test. It is shown that 


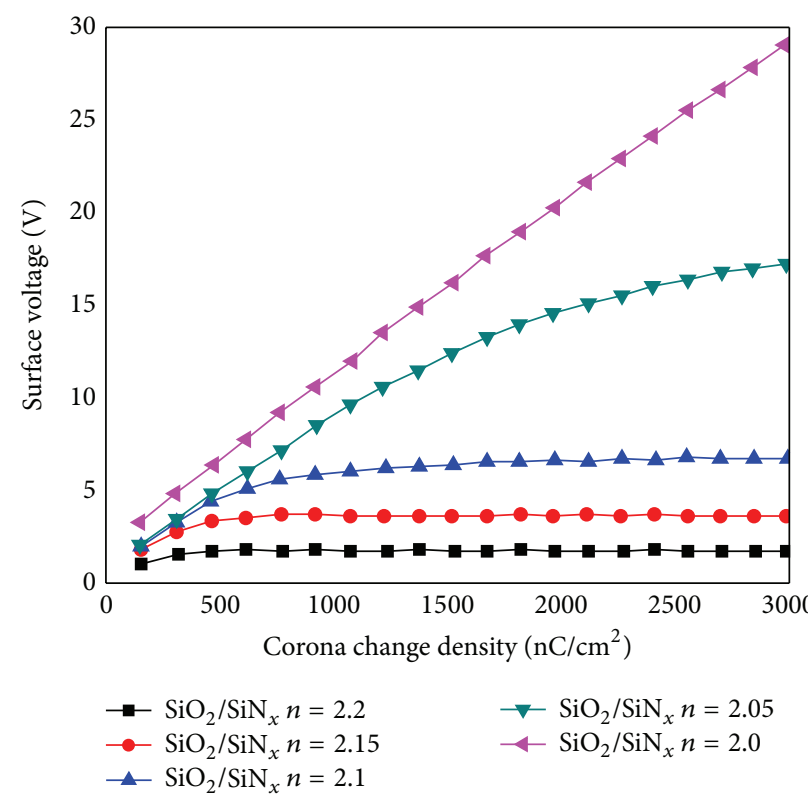

(a) V-Q measurement

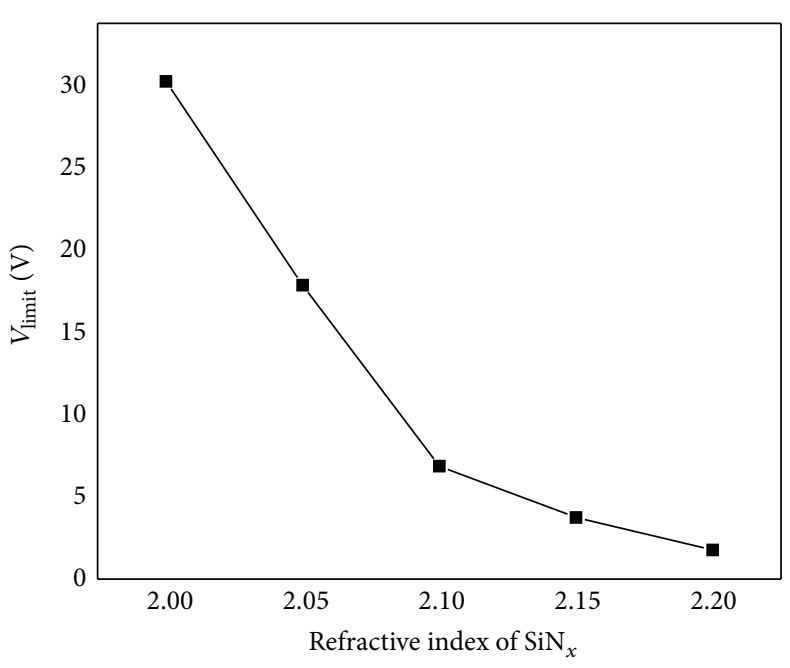

(b) Relation between $V_{\text {limit }}$ and refractive index of $\mathrm{SiN}_{x}$

Figure 4: Testing results of V-Q and $V_{\text {limit }}$ with different refractive index of $\operatorname{SiN}_{x}$.

$R_{\mathrm{sh}}$ test can be used as quality inspection of solar cells and V$\mathrm{Q}$ test of coated wafer can be used as process control of solar cells. Those two methods can be helpful to eliminate PID in mass production level.

\section{Conflict of Interests}

The authors declare that there is no conflict of interests regarding the publication of this paper.

\section{Acknowledgments}

The authors would like to thank Dr. Chunlan Zhou for helpful discussions and review of this paper. The authors would also like to thank Dr. Jacky Ren from Semilab Co., Ltd., for the measurement of V-Q test and helpful discussions.

\section{References}

[1] R. Swanson, M. Cudzinovic, D. DeCeuster et al., "The surface polarization effect in high-efficiency silicon solar cells," in Proceedings of 15th International Photovoltaic Science and Engineering Conference (PVSEC '05), Shanghai, China, 2005.

[2] P. Hacke, R. Smith, K. Terwilliger et al., "Acceleration factor determination for potential-induced degradation in crystalline silicon PV modules," in Proceedings of the IEEE International Reliability Physics Symposium (IRPS '13), pp. 4B.1.1-4B.1.5, Anaheim, Calif, USA, April 2013.

[3] P. Hacke, R. Smith, K. Terwilliger et al., "Testing and analysis for lifetime prediction of crystalline silicon PV modules undergoing degradation by system voltage stress," in Proceedings of the 38th IEEE Photovoltaic Specialists Conference (PVSC '12), pp. 1750-1755, IEEE, Austin, Tex, USA, June 2012.
[4] S. Pingel, O. Frank, M. Winkler et al., "Potential induced degradation of solar cells and panels," in Proceedings of the 35th IEEE Photovoltaic Specialists Conference (PVSC '10), pp. 2817-2822, Honolulu, Hawaii, USA, June 2010.

[5] P. Hacke, R. Smith, K. Terwilliger et al., "Testing and analysis for lifetime prediction of crystalline silicon PV modules undergoing degradation by system voltage stress," IEEE Journal of Photovoltaics, vol. 3, no. 1, pp. 246-253, 2013.

[6] C. Taubitz, M. Schütze, and M. Köntopp, “Towards a kinetic model of potential-induced shunting," in Proceedings of the 27th European Photovoltaic Solar Energy Conference, pp. 3172-3176, Frankfurt, Germany, September 2012.

[7] M. Schütze, M. Junghänel, M. B. Koentopp et al., "Laboratory study of potential induced degradation of silicon photovoltaic modules," in Proceedings of the 37th IEEE Photovoltaic Specialists Conference (PVSC '11), pp. 821-826, IEEE, Seattle, Wash, USA, June 2011.

[8] K. Mishina, A. Ogishi, K. Ueno et al., "Investigation on antireflection coating for high resistance to potential-induced degradation," Japanese Journal of Applied Physics, vol. 53, no. 3, 2014.

[9] P. Hacke, K. Terwilliger, R. Smith et al., "System voltage potential-induced degradation mechanisms in PV modules and methods for test," in Proceedings of the 37th IEEE Photovoltaic Specialists Conference (PVSC '11), pp. 000814-000820, Seattle, Wash, USA, June 2011.

[10] H. Nagel, P. Saint-Cast, M. Glatthaar, and S. Glunz, "Inline processes for the stabilization of p-type crystalline Si solar cells against potential-induced degradation," in Proceedings of the 29th European PV Solar Energy Conference and Exhibition, Amsterdam, The Netherlands, September 2014.

[11] M. Wilson, A. Savthouck, J. D’Amico et al., "Importance of defect photoionization in silicon-rich SiNx dielectrics for high PID resistance," in Proceedings of the 39th IEEE Photovoltaic Specialists Conference (PVSC '13), pp. 218-222, IEEE, Tampa, Fla, USA, June 2013. 
[12] M. Wilson, A. Savtchouk, P. Edelman, D. Marinskiy, and J. Lagowski, "Drift characteristics of mobile ions in SiNx films and solar cells," Solar Energy Materials and Solar Cells, vol. 142, pp. 102-106, 2015.

[13] S. Goranti and G. TamizhMani, "Potential induced degradation (PID) study on accelerated stress tested PV modules," in Proceedings of the 38th IEEE Photovoltaic Specialists Conference (PVSC '12), pp. 2438-2441, IEEE, Austin, Tex, USA, June 2012.

[14] V. Naumann, D. Lausch, S. Großer et al., "Microstructural analysis of crystal defects leading to potential-induced degradation (PID) of Si solar cells," Energy Procedia, vol. 33, pp. 76-83, 2013.

[15] D. Lausch, V. Naumann, O. Breitenstein et al., "Potentialinduced degradation (PID): introduction of a novel test approach and explanation of increased depletion region recombination," IEEE Journal of Photovoltaics, vol. 4, no. 3, pp. 834840,2014 

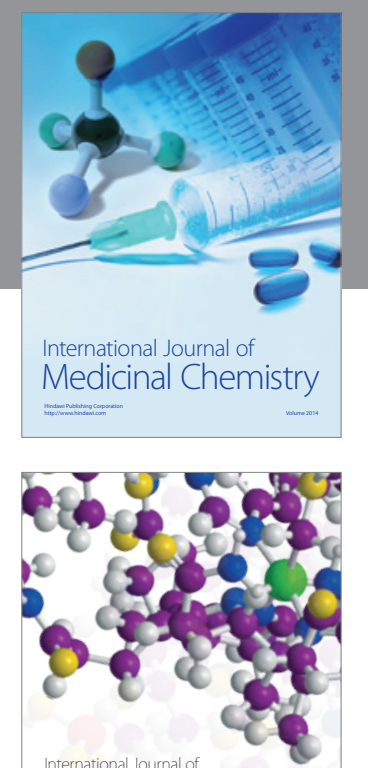

\section{Carbohydrate} Chemistry

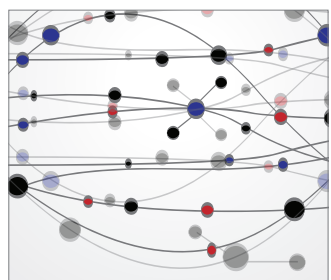

The Scientific World Journal
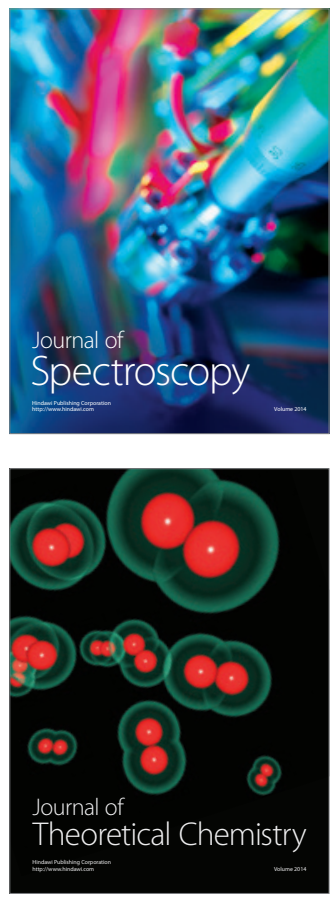
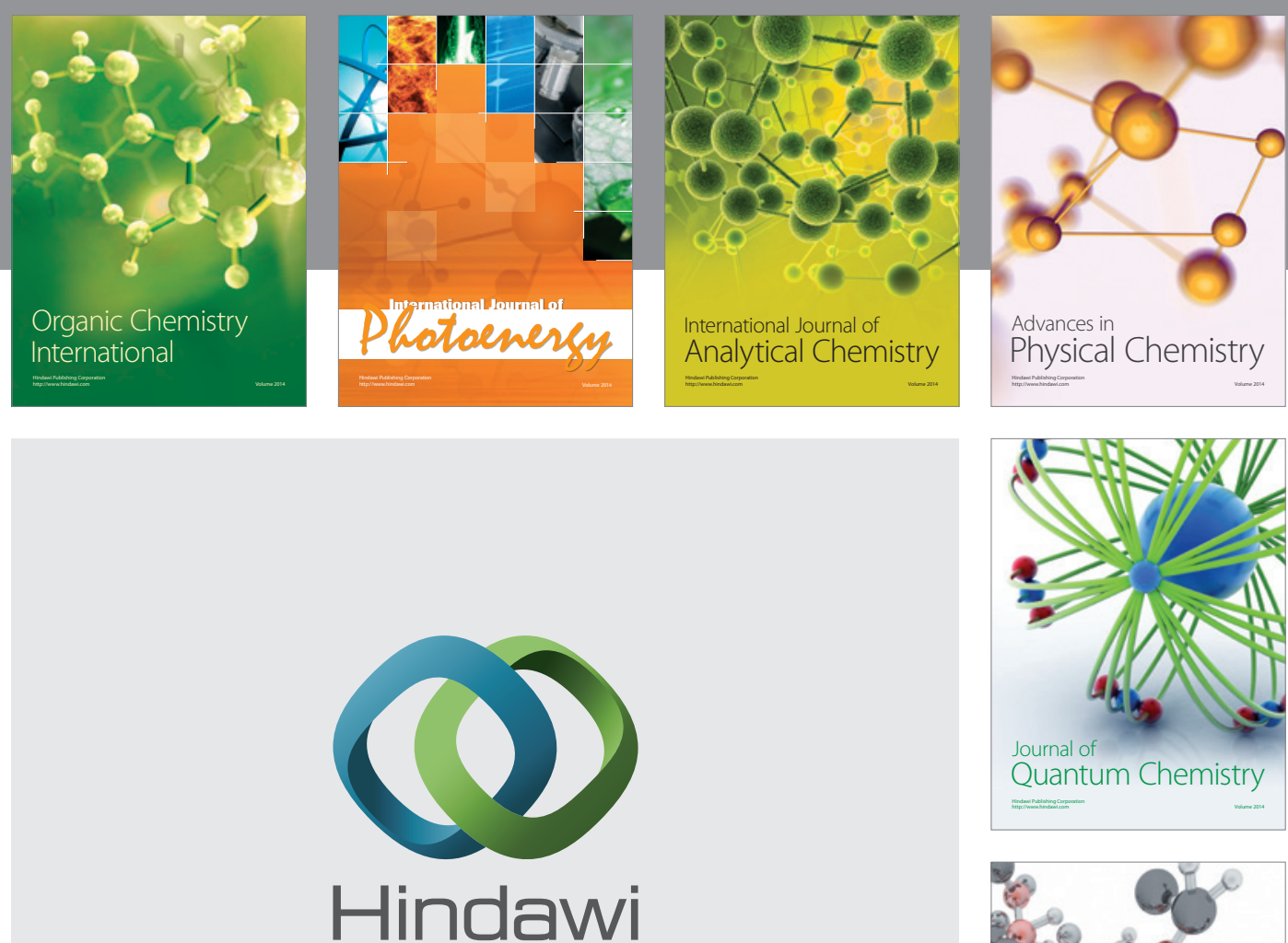

Submit your manuscripts at

http://www.hindawi.com

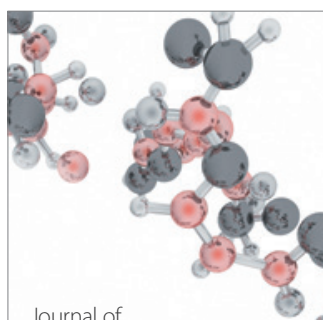

Analytical Methods

in Chemistry

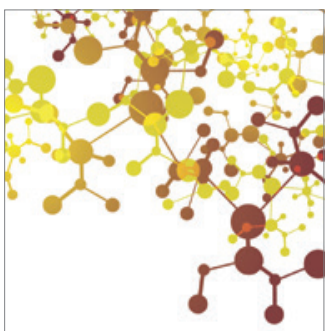

Journal of

Applied Chemistry

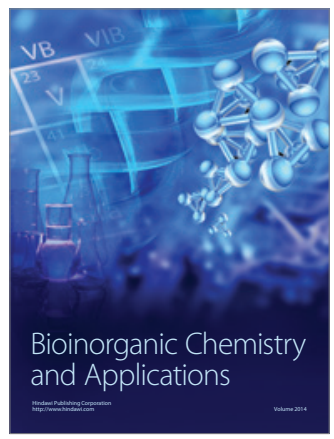

Inorganic Chemistry
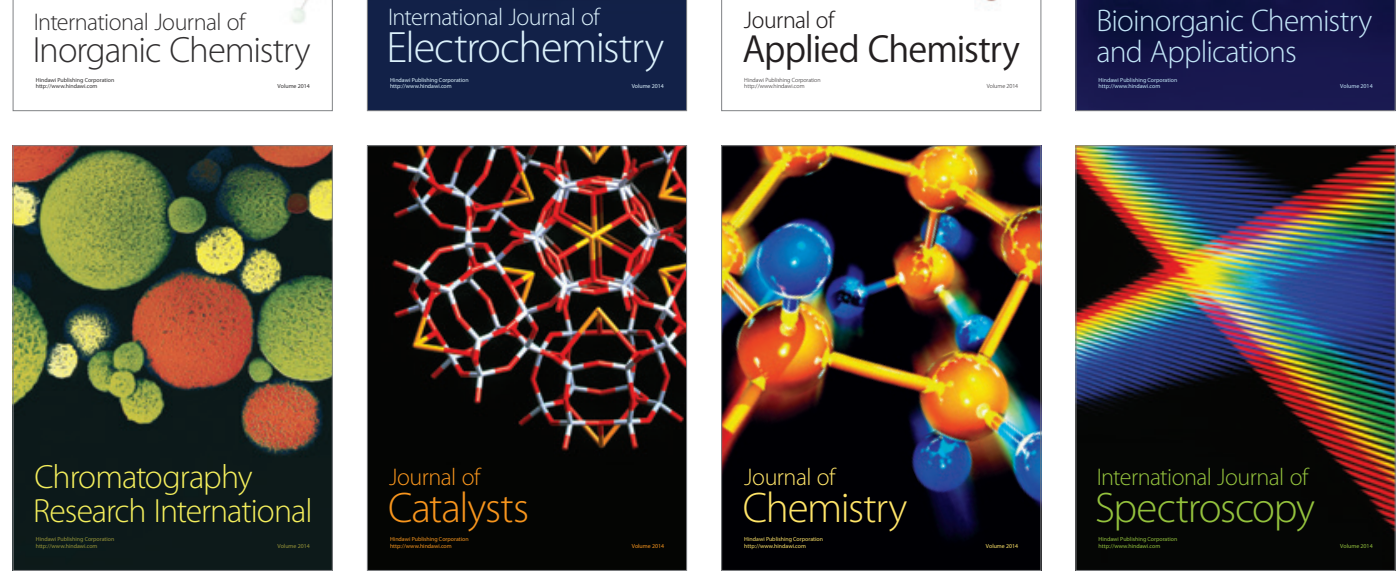